\title{
Practice of Peer Instruction in Computer Experiment Courses
}

\author{
Ying Chen and $\mathrm{Yi} \mathrm{Xu}$ \\ School of Mathematics and Information Engineering, Taizhou University \\ No.605 Dongfang RD, Linhai, Taizou, Zhejiang, China \\ ychen222@tzc.edu.cn
}

\begin{abstract}
In recent years, the wave of information technology is sweeping the world, and computer experiment education has drawn worldwide attention. On the foundation of 10 years' computer experiment education experience, and taking the characteristics of Chinese undergraduate students into consideration, Taizhou University improved the previous teaching mode, and formed an integrated-teaching mode with the Peer Instruction (PI) as a core which also combined the thought of "the flipped classroom". After one year's exploration and practice, it is found that this mode more easily stimulates the enthusiasm and initiative of students, enhances their cooperative ability, innovative thinking and hands-on spirit. The experiment achievements and feedbacks from students prove that this teaching mode largely realized the goal of the courses.
\end{abstract}

Keywords: Peer Instruction, Flipped classroom, Teaching mode, Computer experiment education

\section{Introduction}

With the rapid development of information science and technology, computer experiment education has become an indispensable part in university. Compared with teaching of theoretical courses, the teaching of computer experiment courses is intuitive, practical, instructive and exploratory, plays an important role in cultivation of students' practical ability and innovative thinking. In major of computer, there are many kinds of knowledge points and various experiment methods involved in the experiment courses. Only participating through the practice, students can achieve the learning purpose of mastering knowledge and improving the practical ability. But the traditional teaching mode only depends on the oral narration or the multimedia courseware, which cannot teach the key examples to each student. Students may understand the purpose and principles of the experiment, but cannot be able to remember the details of the steps and specific considerations, which led to low efficiency of the experiment process. Moreover, the final result may be not very good.

Peer Instruction (PI) is a kind of student-oriented mutual support teaching strategy. It can be used to examine the level of mastery of learners and their peers. In the case of the team learning, every student can teach the team members from teachers' perspectives. At the same time, they can receive guidance and help from the companions. It will greatly enhance the enthusiasm of learning, broaden the thinking dimension, depth understanding of knowledge, and improve the ability to innovate and so on [1-2]. The learners themselves to improve the efficiency of learning at the same time to overcome the basic ability of different courses difficult, inadequate teaching resources and other issues, which reduce the burden of teachers in the experimental course.

This paper combines the idea of "the flip classroom", and puts forward the application of Peer Instruction strategy in computer experiment courses. The teaching mode carefully

Received (July 6, 2017), Review Result (September 18, 2017), Accepted (December 20, 2017) 
considers the University background and environment, the characteristics of curriculums, students' psychological and other factors, covering the pre-class, in-class and after class. The features of PI teaching mode, summarized as flipped classroom based, project practice, team division of labor and cooperation, promote the computer experiment courses teaching to acquire favorable results.

\section{Teaching Mode}

\subsection{Peer Instruction Teaching Strategy}

The word 'PI' first appeared in the late nineteenth century. Andrew Bell and Joseph Lancaster have adopted the monitorial system in the poor school, which is the first systematic organization of peer teaching [3]. The guide system refers to that the high grade students to guide the lower grade students in order to promote the progress of the general students' achievement. It eased the lack of teachers and funding problems, which promote the development of education in the United Kingdom in nineteenth century. And the new period of peer teaching is that each student can stand in the dominant position, conducive to the construction of learning atmosphere, whose purpose is that all the students to make progress together. In the last century in 90s, Professor Eric Mazur, a physics professor at Harvard University, first proposed the real application to modern higher education [4-5].

Since then, PI teaching strategy began to be popularized, such as in linear algebra course [6] and in chemistry flipped classroom [7]. In addition, it also has some research on the development of PI [8-9] and the comparison of PI teaching strategy and other teaching methods [10]. However, PI has scarcely been used in computer experiment course. Only Taiwan (ROC, Republic of China) scholars propose pair programming mode in the data structure course [11], and practice has proved that the teaching effect of PI in the computer science course is more remarkable [12-14].

The current situation shows that the research and development of PI is more and more comprehensive, and there also has researches on the application of PI into computer science courses. However, the application of PI in higher education is still relatively a little bit. The discipline characteristic of computer experiment is strong in technology and application, and it needs to be closely connected with practice and theory. So it is very necessary to carry out the research of PI in computer experiment from the point of view of students' learning psychology.

\subsection{Teaching Program}

Our teaching program pays more attention to the connotation of PI, focusing on the students as the main body of learning. The teacher's main task is to carry out the knowledge point screening, experimental design and task deployment before the class firstly. Then teacher needs to ask questions, supervise and assist in class. At last, teacher check, summarize and improve the work after class. In addition, the teacher needs to examine the results of the experiment, record the time spent on the success of the team and take extra points for the excellent team, to create a competitive environment under the teams learning atmospheres, which can promote the autonomous learning of each team members. At the end of the class, a brief summary report will be made. The teacher will randomly assign one member of a team to talk about the feelings, and answer the questions given by teacher. The questions embrace the experimental knowledge points, in order to test whether the students have mastered this chapter experiment content, or have the ability of application. (The final result $=$ the simulation experiment $* 20 \%+$ actual operation $* 35 \%+$ class performance $* 15 \%+$ experiment report $* 30 \%$ ).

The teaching program is shown in Figure 1. 


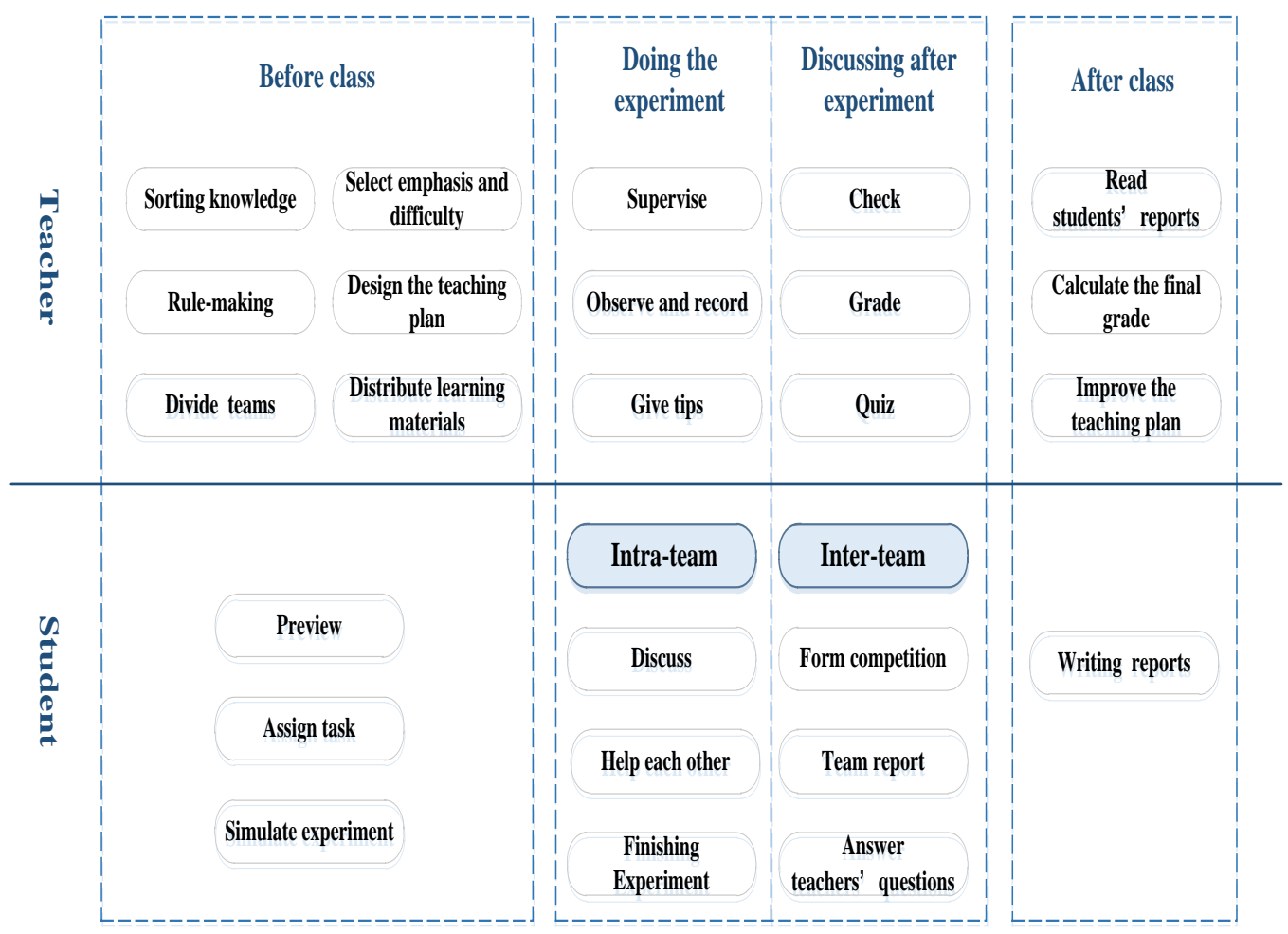

Figure 1. Teaching Program

\section{PI process, Results and Evaluation}

\subsection{Process}

Taking the experimental course of < Computer network engineering> as an example, the implementation of teaching program is shown in Figure 2.

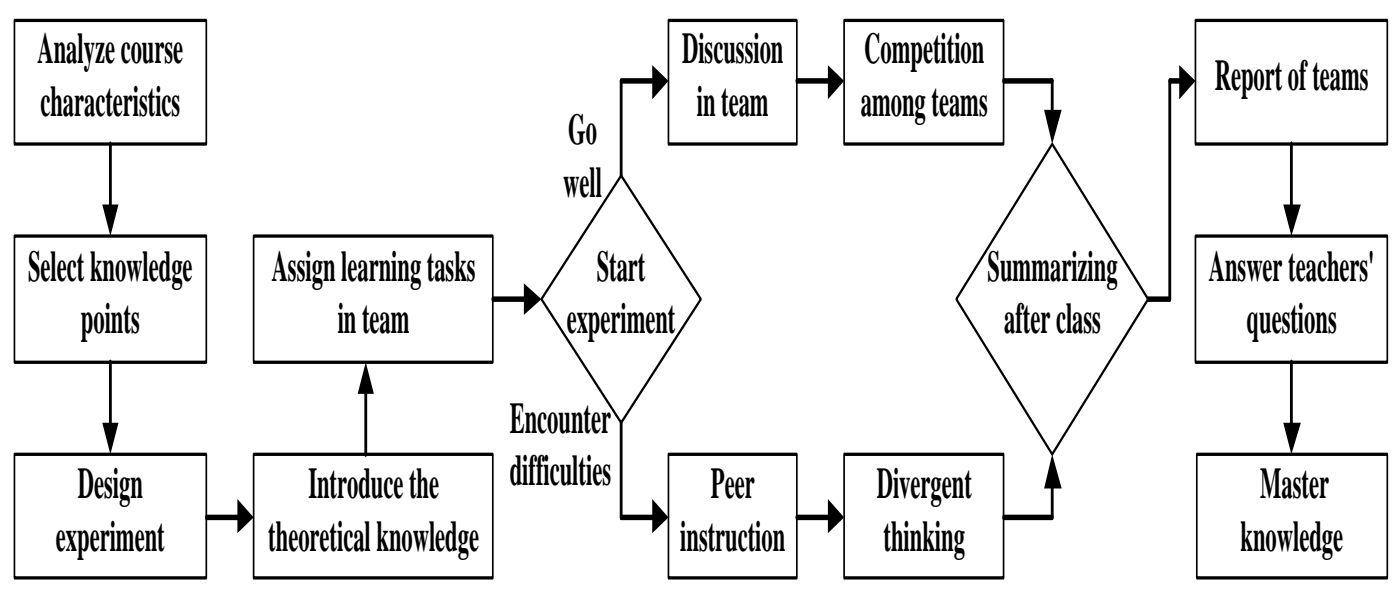

Figure 2. PI implementation Process 
Before the class, the teacher assigned the task of teaching. The students began to preview and advance the simulation experiment. In the course of the class, the students are teamed to discuss the difficulties that arise in the simulation experiment. When necessary, the teacher may give some hints. But the overall teaching center is mainly based on the students. At the end of the experiment, the students report and answer questions, so as to investigate their learning situation. After class, the students complete their respective experimental reports. Teacher summarizes the results of the whole experiment, in order to promote the improvement of teaching method.

\subsection{Results}

In the practice of PI in experimental course of < Computer network engineering>, 24 teams all finished the specified tasks satisfactorily with various methods. Each team has its characteristics and features. After a semester's trial, the results are remarkable. Students have a better mastery of the experiment contents. These students can explore further and get more involved in the study than those who learned in the previous year. Teachers and students have more communications and get more closed than before, Students' communication skills have been practiced and reinforced greatly and critical thinking has been cultivated and developed.

According to the grade of final exam, compared with the same period of traditional teaching methods, students' scores increased significantly. And the failure rate decreased while the percentage of excellent people rose. The majority of students said they really learned knowledge, with a sense of success in the experiment. The final exam scores are shown in Figure 3.

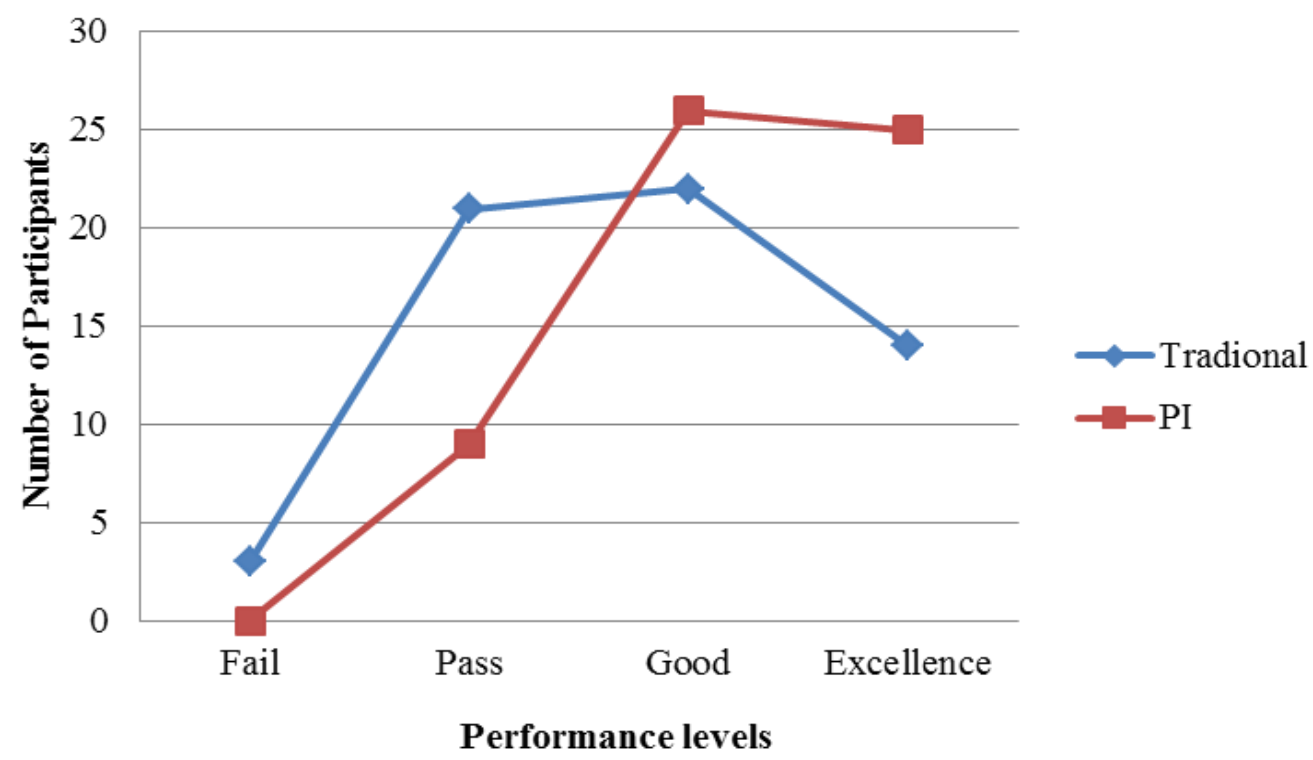

Figure 3. Statistics Chart of Students' Achievement in Two Teaching Environments

\subsection{Performance Evaluation}

We conducted a questionnaire survey of students at the end of the term. The questionnaire is shown in Table 1, which includes the evaluation of the experimental link, the changes of the learning psychology, the feeling of individual harvest and so on. At the end of the semester, every student who chooses the course will receive it. A total of 120 questionnaires were issued, and 118 copies were recovered. 
Table 1. Students' feedback on Teaching Effectiveness Questionnaire

\begin{tabular}{|c|c|c|c|c|c|c|c|c|c|}
\hline \multirow{2}{*}{ No. } & \multirow{2}{*}{ question } & \multicolumn{4}{|c|}{ Traditional mode } & \multicolumn{4}{|c|}{ PI mode } \\
\hline & & & B & $\mathrm{C}$ & $\mathrm{D}$ & A & B & $\mathrm{C}$ & D \\
\hline \multirow[t]{2}{*}{1} & Through the experiment, can fully grasp the knowledge & & & & & & & & \\
\hline & of it? & & & & & & & & \\
\hline 2 & Interest and enthusiasm in learning is raised? & & & & & & & & \\
\hline 3 & Innovative thinking is to be demonstrated and training? & & & & & & & & \\
\hline \multirow[t]{2}{*}{4} & In the course of the experiment, whether the leadership is & & & & & & & & \\
\hline & important? & & & & & & & & \\
\hline 5 & In the course of the experiment, is teamwork important? & & & & & & & & \\
\hline 6 & When an experiment is done, it takes a lot of time? & & & & & & & & \\
\hline 7 & Feel that data collection and documentation is important. & & & & & & & & \\
\hline 8 & Harvest a lot of knowledge from the discussion session. & & & & & & & & \\
\hline \multirow[t]{2}{*}{9} & To complete implementation of the experiment, I formed & & & & & & & & \\
\hline & a preliminary concept of the system. & & & & & & & & \\
\hline 10 & Other suggestions/feelings: & & & & & & & & \\
\hline
\end{tabular}

*A to D on behalf of the recognition of the degree of diminishing.

The survey results show in Figure 4.

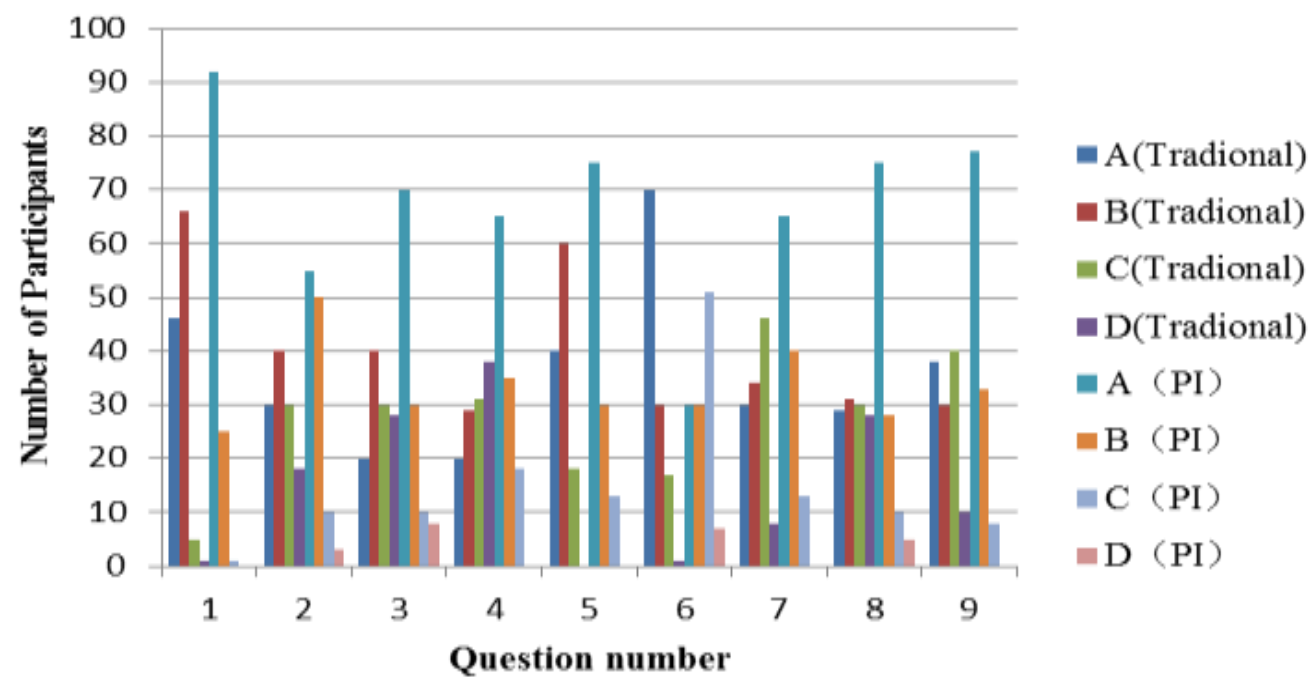

Figure 4. Statistics Chart about Students' Feedback on Teaching Effect

Analysis of data and the results of the same period confirmed that the PI has the following advantages.

(1) Stimulate students' interest in study

According to the statistical data of question 2, the students largely have expressed their interest in computer experiment in general. And there are a lot of students express the experience of the experimental study through the "feeling" column. They said that their 
individual's sense of participation and achievement are higher in the PI environment, which is the motivation for the students to carry out the next experiment.

(2) Promote the development of a good learning habit

In the traditional classroom, students' participation is low. They did not have the consciousness to take notes, and did not develop good learning habits. From feedback from the question 7 and 8, and now after each experiment of mutual learning, their participation is higher. They have their own understanding of the knowledge. Therefore, with the idea of summary, they gradually develop a good learning habit.

(3) To put an end to the occurrence of low-level errors

At the time of the experiment, each step is carried out under the common cooperation. Everyone has his own independent thinking. In such an atmosphere, it is comprehensive to consider the problem. The experiment will not be carried out because of personal negligence, which avoids wasting valuable time and energy.

(4) To promote good results

Because each person's way of thinking is different, so the way to deal with it is also different. For example, in the course of the experiment, no matter whether the progress of the experiment is successful or not, when there are members to ask questions, there are other members to answer these questions. When helping solving others' questions, there may be some mistakes. But under the discussion, not only the problem can be solved, but also can be found in a variety of ways to complete the experiment.

(5) Developed a comprehensive ability

During the discussion, in order to elaborate their own opinion, students will take the initiative to find relevant information and experimental data to prove their views. If things go on like this, the students in an argument can be harvested in the knowledge which improves the ability to summarize and communicate. Similar information can be obtained from the chart. Students pay more attention to data collection and documentation. What's more, they attach importance to getting leadership and presentation skills.

\section{Conclusion}

Compared data records in previous years, students have better grades who taught by the PI teaching method. At the same time, the rate of fail is greatly reduced, while the number of excellence is also relatively large. According to observation from the teacher, the atmosphere is good and the enthusiasm of talking topic is raised. And students' active performance has broken down the dull atmosphere in college experimental class. At the same time, the students often ask questions and solve other members' questions. Gradually, everyone's participation is higher. They enhanced the individual selfconfidence and stimulated the interest of learning while acquire the sense of achievement after the successful experiment.

Some problems are also reflected in the experiment.

College teaching environment, students' learning psychology, and curriculum characteristics and so on are all factors of designing the teaching program. Take some colleges and universities as examples, in the setting up of a computer course, there usually will be the following shortcomings: First, during the experiment teaching in large class, teachers cannot take care of every students while students' doubt often is not promptly resolved. Second, laboratory technical strength is limited. Equipment has a number of shortcomings, lack of parts, quality aging and other issues. And the poor contact and the lack of important components is often one of the reasons for the failure of the experiment. Third, teaching focuses on the presentation of the results and the verification conclusion, which will limit the ability of students to develop and solve the derivative case. It leads 
students only to deal with the cases from teachers, and cannot apply the knowledge to life, which is contrary to the original intention of the study.

The results of the survey about students' learning psychology reflected the following performance when they are studying computer courses: First, poor self-control caused a lack of motivation to learn. Experimental course content not only involves theoretical knowledge but also contains the actual operation, it is necessary to review and preview the work. And students are often distracted by their school life. When missing these crucial links, this will lead to a significant reduction in learning efficiency. Second, learning motivation is weak, which is the lack of motivation and courage to overcome difficulties. When face the experimental and expected results are not consistent or a step does not go on, they will choose to refer to the existing solutions or give up. This leads to the lack of time for students to think independently, so that memory remains in the surface. And ultimately, it leads to poor learning ability and weak professional knowledge. Third, students rely on teaching materials or teachers' guidance is a serious phenomenon. For example, in programming classes, they rely on the code from the book, and not to take time to think or create. When there is an error in the program, they rely on help from the teacher to solve instead of their own first to debugging or checking the code. The time for students to think independently is getting less and less because of the bad psychological habit. What's more, they lack the consciousness of innovation and independent study, which cause great limitation to the improvement of students' ability.

About the characteristics of the computer experimental class, it involves a wide range of knowledge. And the front and back chapters are closely related among the experiment. In the field of computer research, because of its wide range of technical development and rapid innovation, colleges and universities in the training of technology applied talents need to consider the new technology to teach, to complete the transfer of social talent output. Therefore, how to grasp the basic theoretical knowledge and master the ability of the experimental operation skillfully, and follow the rapid technological innovation is the teaching goal and the difficulty of the computer experiment course.

In the atmosphere of PI, students have more chances to show themselves. But there is also an extreme negative effect. For example, students who are weak in basic knowledge will blindly believe or rely too much on students because of their excellent performance. It will cause them not to take the initiative to think or to do it for their low participation. Even in the team reporting or classroom summary, it cannot be fully investigated whether this part of the students really mastered the knowledge. In view of the existing problems, we still need to continue to explore, refer to the advanced teaching cases at home and abroad, to sum up to further optimize the teaching method of PI.

\section{Acknowledgments}

This work was supported by the Reform Programme of Higher Education in Zhejiang Province of China under Grant No.kg2015427.

\section{References}

[1] C. B. Lee, S. Garcia and L. Porter, "Can peer instruction be effective in upper-division computer science courses", ACM Transactions on Computing Education (TOCE), vol. 13, no. 3, (2013), pp. 12.

[2] C. Taylor, J. Hummel, D. Hovemeyer, D. Bunde, J. Dooley and J. Spacco, "Peer Instruction in Practice", Proceedings of the 2017 ACM SIGCSE Technical Symposium on Computer Science Education, Seattle, Washington, USA, (2017) March 08-11.

[3] R. Rayman, "Joseph Lancaster's Monitorial System of Instruction and American Indian Education, 1815-1838", History of Education Quarterly, vol. 21, no. 4, (1981), pp. 395-409.

[4] E. Mazur, "Peer instruction", Prentice Hall, Upper Saddle River, NJ, America, (2013).

[5] E. Mazur, "Peer instruction: getting students to think in class", AIP Conference Proceedings, vol. 399, no. 1, (1997), pp. 981-988. 
[6] B. Love, A. Hodge, N. Grandgenett and A. W. Swift, "Student learning and perceptions in a flipped linear algebra course", International Journal of Mathematical Education in Science and Technology, vol. 45, no. 3, (2014), pp. 317-324.

[7] J. Schell and E. Mazur, "Flipping the chemistry classroom with peer instruction", Chemistry Education: Best Practices, Opportunities and Trends", WI LEY-VCH Verlag GmbH \& Co. KGaA, Weinheim, Germany, (2015).

[8] N. Michinov, J. Morice and V. Ferrières, "A step further in Peer Instruction: Using the Stepladder technique to improve learning", Computers \& Education, vol. 91, (2015), pp. 1-13.

[9] B. Simon and Q. Cutts, "Peer instruction: A teaching method to foster deep understanding", Communications of the ACM, vol. 55, no. 2, (2012), pp. 27-29.

[10] J. Morice, N. Michinov, M. Delaval, A. Sideridou and V. Ferrières, "Comparing the effectiveness of peer instruction to individual learning during a chromatography course", Journal of Computer Assisted Learning, vol. 31, no. 6, (2015), pp. 722-733.

[11] Y. F. Yang, C. I. Lee and C. K. Chang, "Learning motivation and retention effects of pair programming in data structures courses", Education for Information, vol. 32, no. 3, (2016), pp. 249-267.

[12] B. Simon, S. Esper, L. Porter and Q. Cutts, "Student experience in a student-centered peer instruction classroom", Proceedings of the ninth annual international ACM conference on International computing education research, San Diego, San California, USA, (2013) August 12-14.

[13] L. Porter, L. C. Bailey and B. Simon, "Halving fail rates using peer instruction: a study of four computer science courses", Proceeding of the 44th ACM technical symposium on Computer science education, Denver, Colorado, USA, (2013) March 06-09.

[14] B. Simon, J. Parris and J. Spacco, "How we teach impacts student learning: peer instruction vs. lecture in CSO", Proceeding of the 44th ACM technical symposium on Computer science education, Denver, Colorado, USA, (2013) March 06-09. 